\title{
Investigating possible links between the North Atlantic Oscillation and rainfall variability in northwestern France over the past 35 years
}

\author{
N. Massei, ${ }^{1}$ A. Durand,${ }^{1}$ J. Deloffre,${ }^{1}$ J. P. Dupont, ${ }^{1}$ D. Valdes,${ }^{1}$ and B. Laignel ${ }^{1}$ \\ Received 16 December 2005; revised 5 November 2006; accepted 13 December 2006; published 15 May 2007.
}

[1] In this paper, the temporal dynamics of precipitation in northwestern France in relation to the dominant climatic pattern in Europe were investigated. The general trends and the nonstationary behavior of the North Atlantic Oscillation (NAO) were described using fractal analysis and Fourier spectral and continuous wavelet analysis of a NAO index time series over the 1865-2004 period. The 44-year and 8-year multidecadal components showed a clear increasing power during the second half of the last century. The possible link between rainfall variability and the NAO was then investigated. The links between the NAO and rainfall were not as obvious, as NAO-like components were not easily retrieved in the precipitation records: Relationships between the NAO and rainfall were very likely at certain timescales but were not systematically very obvious. For instance, the characteristic quasi-biennal oscillation (QBO) of the NAO was barely detected in precipitation, but a $\approx 6$-year fluctuation beginning in the 90 s was found to be statistically significant at a $95 \%$ confidence limit After investigating a possible link with the Southern Oscillation Index, the occurrence of this fluctuation in the beginning of the 90 s could be related to the observed shift of the QBO toward slightly higher frequencies in the NAO time series. On the other hand, a modulation of the QBO by a $\approx 6$-year interannual fluctuation would suggest the existence of $\mathrm{a} \approx 6$-year climate pattern that could affect precipitation and, to a lesser extent, the NAO. Cross-wavelet analysis between the NAO and precipitation revealed a loss in correlation across the 1970-2005 period, which seemed to be the fact of a QBO-like fluctuation. This loss of correlation was related to the above-mentioned shift of the QBO and 6-year rainfall interannual band since the $90 \mathrm{~s}$.

Citation: Massei, N., A. Durand, J. Deloffre, J. P. Dupont, D. Valdes, and B. Laignel (2007), Investigating possible links between the North Atlantic Oscillation and rainfall variability in northwestern France over the past 35 years, J. Geophys. Res., 112, D09121, doi:10.1029/2005JD007000.

\section{Introduction}

[2] Climate change is one of the more challenging issue of the last decade. In Europe, the North Atlantic Oscillation (NAO) reflects the main fluctuations of climatic conditions [Hurrell, 1995; Hurrell and Van Loon, 1997]. The relationships between NAO and both global and local weather patterns such as precipitation and storm track activity [Rogers, 1997; Ulbrich and Christoph, 1999; Ulbrich et al., 1999; Mares et al., 2002; Keim et al., 2004], ecosystems dynamics [Greene and Pershing, 2000; Parsons and Lear, 2001; Greene et al., 2003; Lomas and Bates, 2004], but also contaminant transport in the atmosphere [Macdonald et al., 2005] are wide and complex. NAO prediction then appears of great importance, although the most high-frequency components of the signal make it difficult to achieve good

\footnotetext{
${ }^{1}$ UMR 6143, Continental and Coastal Morphodynamics, Department of Geology, CNRS, University of Rouen, Mont-Saint-Aignan, France.

Copyright 2007 by the American Geophysical Union. 0148-0227/07/2005JD007000
}

predictive models [Bojariu and Gimeno, 2003]. Some authors proposed a description of the NAO temporal variability [Pozo-Vazquez et al., 2000; Fernandez et al., 2003] and faced the difficulty of achieving an accurate description [Fernandez et al., 2003] using classical methods, that usually fail to account for nonstationarities. Appenzeller et al. [1998], Higuchi et al. [1999], Labat et al. [2005b], and Loboda et al. [2006] were among the first to apply wavelet analyses to describe the nonstationary behavior of the NAO. The NAO influence, as well as other climatic patterns such as the El Niño-Southern Oscillation (ENSO) and the Southern Oscillation Index (SOI), has been already detected in subsequent hydrological processes like runoff at the scale of some major rivers in the world [Labat et al., 2005b]. Nevertheless, the complexity of climatic teleconnections sometimes leads to disagreements on their interpretation [Labat et al., 2005a; Legates et al., 2005]. Bojariu and Reverdin [2002] studied the spatial relationship between NAO and rainfall and proposed a reconstruction of precipitation based on the NAO signal, which was found strong enough for precipitation reconstruction to be carried 
out. During the past ten years, as in many places in the world, France has undergone several extreme climatic events like storms (e.g., December 1999), droughts (summer 2003, spring 2005). In this paper, we propose to analyze the possible relationships between NAO and rainfall, and to provide a description of the overall behavior of rainfall in a typical oceanic climate in northwestern France. This study basically aims to address the following general questions that are obviously of great importance at the local scale but are still linked to more global issues like climate variability:

[3] 1. What type of fluctuations are present in precipitation during a 35-year period in northwestern France?

[4] 2. Is it possible to relate some of these fluctuations to the main North Atlantic climatic pattern?

[5] 3. Do these (potentially linked) fluctuations display a constant temporal variability or not?

\section{Description of the Global Patterns of the North Atlantic Oscillation for the 1865-2004 Period}

[6] This section aims to provide a summary of some wellknown general trends of NAO from 1865 to 2004 (Figure 1) based on an annual time series of the station-based NAO index. Its purpose only consists of giving the most accurate description as possible of the NAO in order to better understand its possible long-term trends. Data are available at http://www.cgd.ucar.edu/cas/jhurrell/indices.html. Here, the annual index of the NAO is based on the difference of normalized sea level pressure (SLP) between Ponta Delgada, Azores and Stykkisholmur/Reykjavik, Iceland since 1865.

[7] One should however mention that use of the stationbased NAO index presents, as emphasized by Hurrell et al. [2003], the disadvantage of being fixed in space, which, among others, make it difficult to capture NAO variability for parts of the year inasmuch as the concerned centers of action move throughout the annual cycle. Nevertheless, according to the same authors, station-based indices still offer major advantage of most of these indices is their extension back to the mid-19th century or even earlier.

\subsection{Fourier Spectral and Fractal Analyses}

[8] As a first step, one can compute the Fourier spectrum of the time series, using a Tukey filter: the spectrum is characterized by a power law with a coefficient of 0.2 (Figure 2a). As a result, this NAO annual index time series, with an AR(1) coefficient of 0.14 and a "flat" spectrum, would correspond to a very slightly red noise, as highlighted by Fernandez et al. [2003]. Some peaks that could indicate the presence of periodic structures, especially for periods less than 10 years, are visible. However, only a $\approx 8$-year component appears significant at a $50 \%$ confidence level. Their investigation of the potential influence of Atlantic SSTs on the atmospheric low-frequency variability over the extratropical North Atlantic-European (NAE) region demonstrated a statistically significant tropical SST forcing that could explain $\mathrm{a} \approx 20 \%$ fraction of the interannual NAO variance (ENSO effects removed). According to these authors, the amount of explained SST-forced variance is high in the Tropics, weaker at midlatitudes, and not significant around the Icelandic low region. The corresponding Atlantic
Ocean-Global Atmosphere-type simulations (AOGA, ARPEGE General Circulation Model) exhibited quasidecadal fluctuations with periods comprising a 6-8-year energy band, which can related to the $\approx 8$-year component found herein.

[9] A fractal analysis of the NAO index time series can be used to visualize the global statistical properties of the signal. More precisely, the calculation of the Hurst exponent allows identification of long-range dependence in a data series. It provides as well a means to detect possible thresholds that could occur for specific timescales as a result of periodic components. Fractal analysis is operated by calculating the $\mathrm{R} / \mathrm{S}$ curve of the time series thanks to the growth in cumulative range algorithm (a timescale index is used by partitioning the time series into $\mathrm{n}$ groups of elements and averaging over these groups; for each group, the range $\mathrm{R}$ is then divided by the standard deviation $\mathrm{S}$ of the $\mathrm{n}$ data elements which produce a normalized R/S value called "rescaled range"). Depending on the value of the Hurst exponent (the coefficient of the power law fitting the R/S curve), a signal can be characterized as follow: $\mathrm{H}>0.5 \rightarrow$ persistent autocorrelated signal, $\mathrm{H}=0.5 \rightarrow$ purely Gaussian (white) noise, $\mathrm{H}<0.5 \rightarrow$ antipersistent signal (reverse sign more often as expected, e.g., undamped pure sine). The Hurst exponent of 0.78 confirms that the NAO index time series is not a pure white noise (Figure 2b).

\subsection{Continuous Wavelet Analysis}

[10] As a result of the inefficiency of classic spectral analyses to describe the NAO index time series, we investigated the distribution of power through time using continuous wavelet analysis, which allows an accurate identification of nonstationary features. This same approach has already been successfully applied to the ENSO time series by Torrence and Compo [1998] and recent papers investigated the nonstationary behavior of NAO [Higuchi et al., 1999; Labat et al., 2005b]. The wavelet used for the computation of the continuous wavelet transform of the time series was a derivative of Gaussian (DOG), which produces the well-known Mexican Hat or Marr wavelet for a second-order derivative. Although the DOG wavelet is real valued, the complex component is generated by adding a Heaviside step function $\mathrm{H}(\omega)$ in the frequency domain $(\mathrm{H}(\omega)=0$ for $\omega<0, \mathrm{H}(\omega)=1$ for $\omega \geq 0)$. Here, the derivative order is 14 (the order of the derivative controls the number of oscillations within the wavelet, thus its frequency resolution): the $\mathrm{DOG}_{14}$ wavelet actually seemed to offer the best trade-off between time and frequency resolution compared to the more usual Morlet wavelet, for instance. The continuous wavelet transform is computed on the zero-padded NAO index annual time series (zero padding to the next power of 2 with respect to the data length).

\subsubsection{Component Detection and Global Wavelet} Spectrum

[11] The continuous wavelet transform clearly highlights a highly nonstationary behavior (Figure 3a) of the NAO time series. In Figure $3 \mathrm{a}$, colors indicate the distribution of power (here expressed as normalized decibels, i.e., maximum power $=0 \mathrm{db}$ for each scale), with a decreasing power from purple (max power) to dark red (min power). When tested against a $\mathrm{AR}(1)=0.14$ background red noise, no peak was found to be statistically significant in this annual 


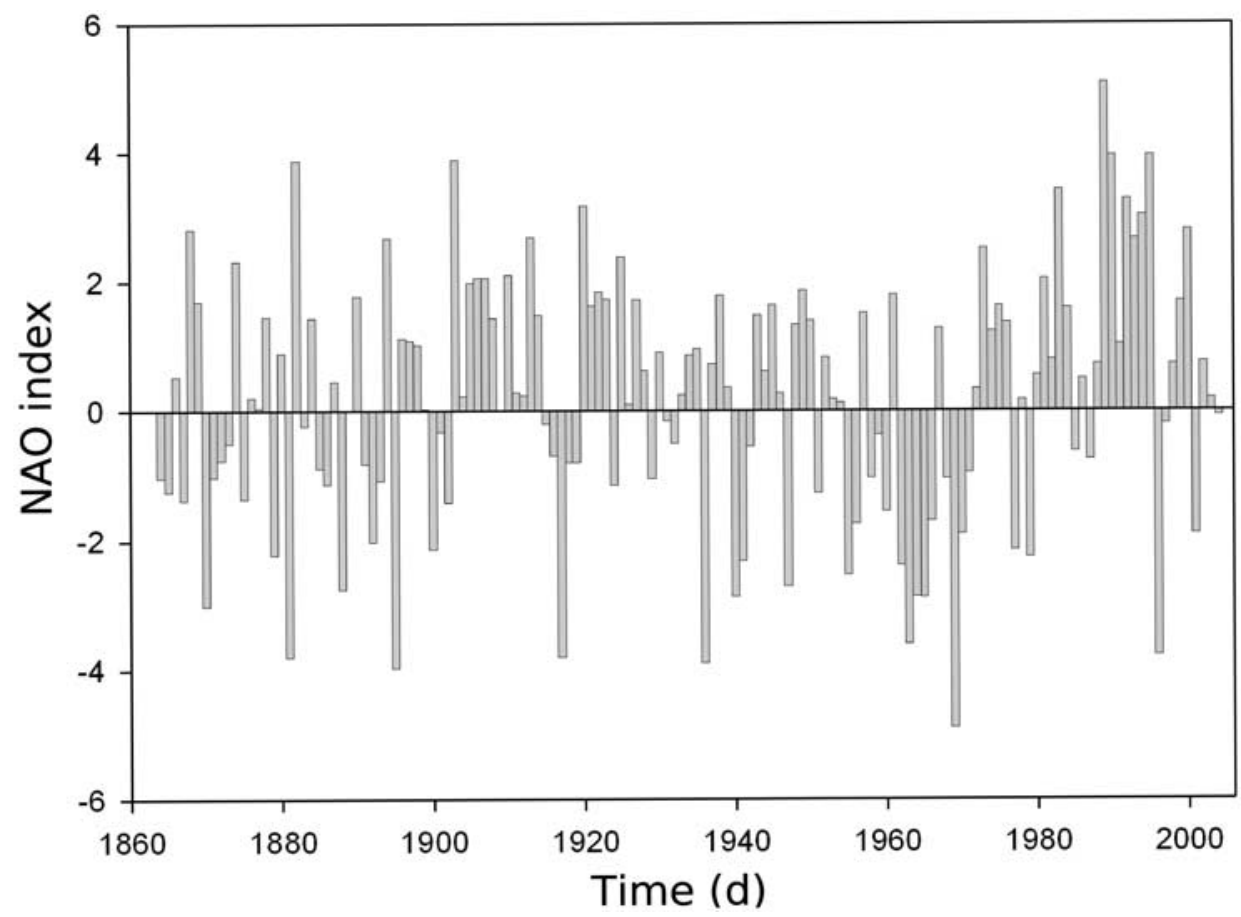

Figure 1. NAO annual index time series since 1865.

time series. Using a white noise background, a $\approx 8$-year fluctuation appears significant at the $50 \%$ confidence level. In brief, although the fractal analysis tends to confirm a red noise behavior, the significance testing of the continuous wavelet spectrum does not show clear statistically significant structured fluctuations.

[12] Although most of the signal does seem to behave randomly, one can still describe the distribution of power on both the local (Figure 3a) and global (Figure 3b) wavelet spectra. Indeed several very localized structures are visible around 2.4 years (corresponding to the so-called quasibiennal oscillation also referred to as QBO), 5.4 years, 8 years, 20.6 years and 44 years. The 44 -year fluctuation, only visible on the local wavelet spectrum (Figure 3a), is probably merged into the 107.9-year trend in the global wavelet spectrum. The comparison of the global wavelet spectrum with a classic Fourier spectrum of the time series clearly explains why many authors provide different values of the spectral components detectable in the NAO index time series, as underlined by Fernandez et al. [2003]. As a matter of fact, the existence of multiple peaks within narrow frequency bands in a classic Fourier spectrum as well as the not easily interpretable number of slope changings of the $\mathrm{R} / \mathrm{S}$ curve number, for instance, only expresses nonstationarity of the various spectral components. On the contrary, the global wavelet spectrum gathers power information
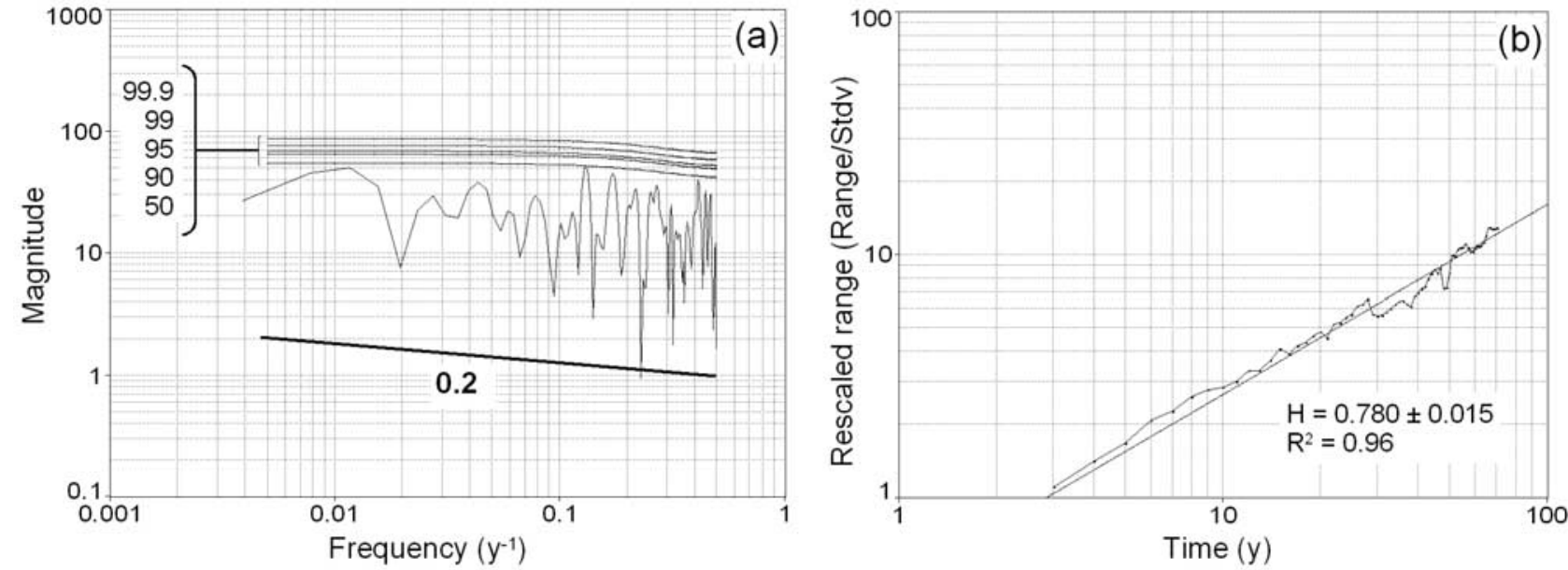

Figure 2. NAO Fourier spectrum and fractal dimension analysis. An $\operatorname{AR}(1)=0.14$ background red noise spectrum is used to define the $50 \%-99.9 \%$ confidence limits for the Fourier spectrum. 

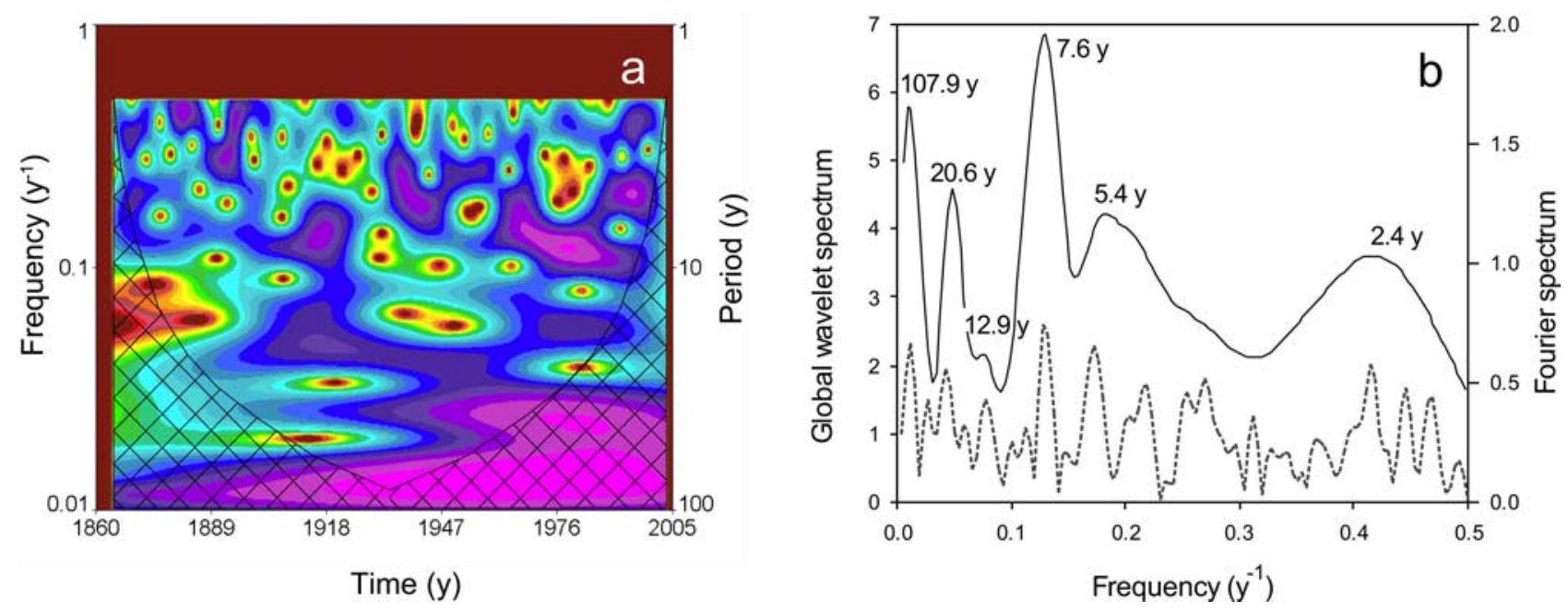

Figure 3. Continuous wavelet spectra of NAO time series (wavelet used, 14th-order derivative of Gaussian): (a) local wavelet spectrum and (b) global wavelet spectrum (solid curve) and Fourier energy spectrum (dashed curve).

which allows a better detection of those frequency bands that contain power while the local wavelet spectrum provides an accurate visualization of changing frequencies.

\subsubsection{Description of the Nonstationary Behavior of the NAO}

[13] As stated above, the local wavelet spectrum (Figure 3a) highlights the changes in frequency of the various components of the NAO index time series. Scale averaging over selected frequency band (Figures $4 \mathrm{~b}-4 \mathrm{f}$ ) as described by Torrence and Compo [1998], used jointly with the local wavelet spectrum, allows to highlight the respective behaviors of the corresponding selected components. In general, the total distribution of power (i.e., averaging over all frequencies) shows an increasing power throughout the 1865-2004 period, which seems to be more effective during the second half of the last century (Figure $4 a$ ). Scale averaging over the $\approx 2.4$-year fluctuation (Figure $4 \mathrm{~b}$ ) shows that the contribution of the QBO to the total variance of the signal is not constant through time and can vary quite significantly, with a great power at the beginning of the time period. The 5.4-year component (Figure 4c) looks very variable either with a high variance between $\approx 1920$ and $\approx 1980$, contrary to QBO. The 8-year fluctuation strongly attenuates between 1925 and 1955, or from the mideighties to nowadays (Figure 4d), that is, precisely during those periods when the previous 5.4-year fluctuation displays an enhanced variability. The 20.6-year component, representing a smaller part in variance, seems to evolve approximately the same way as the 5.4-year fluctuation, whereas the 44-year component increases in power throughout the entire period, more specifically since $\approx 1930$.

[14] In brief, the second half of the last century would be affected by an increasing power of the signal (i.e., a higher variability of the NAO), for most of the components, as underlined by Hurrell and Van Loon [1997]. The distribution of the total power across time (Figure 4a) supports this assertion: a curve fitting with a third-order polynomial reveals quite obviously that the total power tends to increase across the entire 1864-2005 period, and that the increasing trend becomes more and more marked from 1930 approximately.

[15] The scale-averaged power distributions of Figures $4 b-4 f$ show that the 5.4-year, 8-year and 44-year components are the only ones that show a clear increasing power during the second half of the last century.

\section{Rainfall Variability Over the Past 35 Years}

[16] In this section, possible similarities between precipitation and the daily station-based NAO index (Figure 5) are investigated using spectral and continuous wavelet analysis.

\subsection{General Trends}

[17] Precipitation time series recorded in northwestern France are used to analyze the overall tendencies of rainfall over the period of study. 3 pluviometric stations are localized in the Haute-Normandie region $(\approx 150$ northwest of Paris, source: Météo France), and 4 others (kindly provided by Tank et al. [2002] at http://eca.knmi.nl) are homogeneously distributed in the northwest of France: Fatouville-Grestain (within the Seine estuary): lat. $+49: 24: 28$, lon. $+00: 19: 37$, height 102 m; Bois-Arnault: lat. $+48: 48: 45$, lon. $+00: 44: 12$, height 212 m; Marcilly La-Campagne: lat. +48:49:57, lon. +1:13:10, height 140 m; Rennes: lat. +48:04:00, lon. - 01:44:00, height 36 m; Chartres-Champhol: lat. $+48: 27: 42$, lon. $+01: 30: 12$, height 155 m; Paris-14e Parc Montsouris: lat. +48:49:24, lon. $+02: 20: 12$, height $75 \mathrm{~m}$; and Amiens-Glisy: lat. +49:52:18, lon. $+02: 23: 06$, height $60 \mathrm{~m}$. All precipitation time series used are standardized.

[18] The Fourier spectrum of the mean precipitation time series (Figure 6a), hereinafter referred to as $\mathrm{P}_{\mathrm{m}}$, is characterized by two power laws with coefficients of 0.17 and 0.57 , respectively for the long-term part (periods greater than $\approx 25$ days) and the short-term part (periods between 1 day and 25 days). The 0.57 coefficient would give evidence of a structure of rainfall at the short-term scale, possibly related to synoptic events. However, as observed for the NAO index Fourier spectrum, it is still possible to 

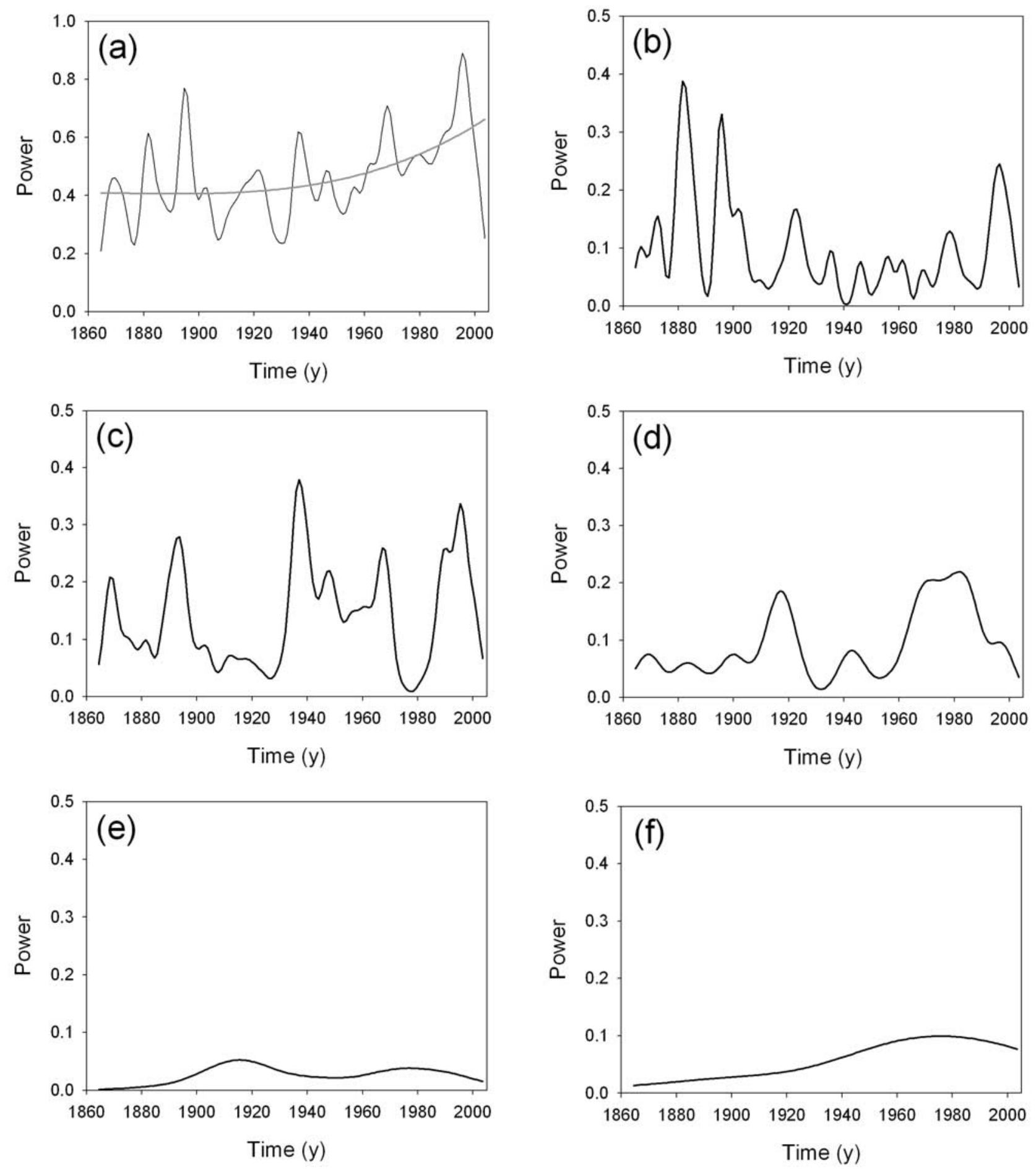

Figure 4. (a) Total power distributions of NAO and scale-averaged power distributions of NAO over frequency bands around the (b) 2.4-year, (c) 5.4-year, (d) 8-year, (e) 20.6-year, and (f) 44-year periods.

distinguish some low-frequency peaks indicating the presence of some periodic structures for periods greater than 25 days.

[19] The fractal analysis of the $\mathrm{P}_{\mathrm{m}}$ time series gives a Hurst exponent of 0.58 and shows that this signal is barely persistent, although not a pure white noise (Figure $6 \mathrm{~b}$ ). It implies that for this $\approx 35$-year period of study, precipitations do not evidence clear long-range dependence properties.

\subsection{NAO and Rainfall Variability: What Significant} Timescales?

\subsubsection{Daily NAO and Precipitation Local Wavelet} Spectra

[20] To investigate the relationships between the NAO and rainfall, the continuous wavelet transforms of the 7 above-mentioned time series are compared to the NAO wavelet spectrum. Figures $7 \mathrm{a}-7 \mathrm{~h}$ display the local wavelet 


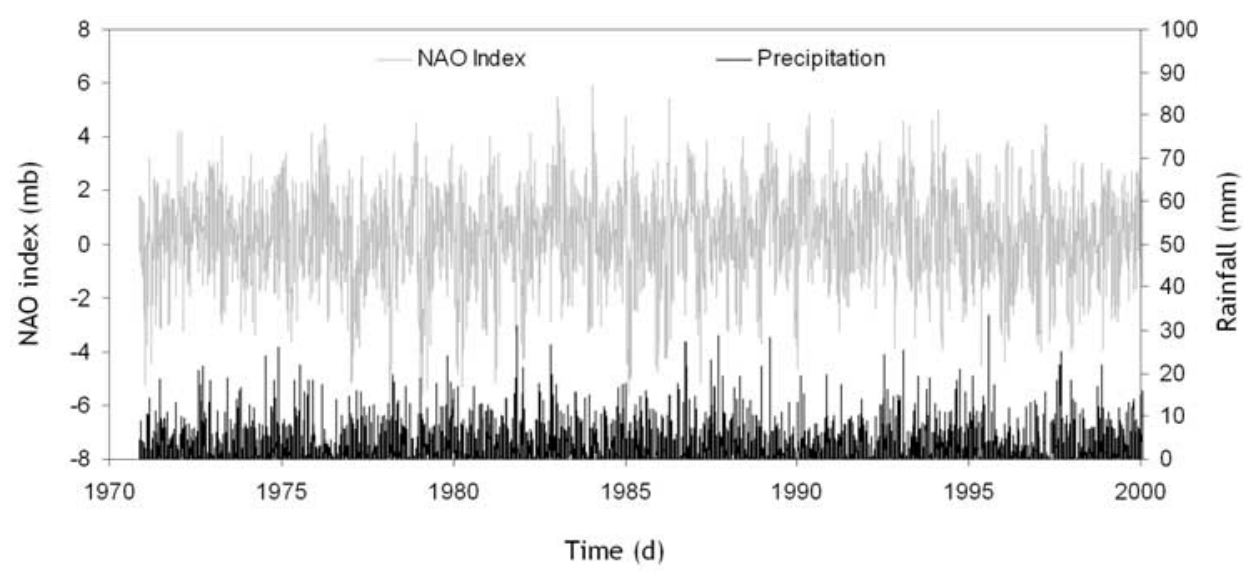

Figure 5. Daily NAO index and mean precipitation time series (computed on the basis of seven pluviometric records in the northwest of France) since 1970.

spectra of 1970-2005 time series of daily NAO index (data available at http://www.cgd.ucar.edu/cas/jhurrell/indices.html) and of the 7 precipitation records, along with the wavelet spectrum of the $\mathrm{P}_{\mathrm{m}}$ series (Figure 8).

[21] All series were zero padded to the next power of 2 with respect to the length of each data set to avoid wraparound effects and spectral leakage. However, padding with zeroes at the ends of the time series implies attenuation of the power of low frequencies, thus producing edge effects. The so-called cone of influence is then represented for each wavelet spectrum by a white-shaded zone, delineating those parts of the wavelet spectrum that are likely to be affected by edge effects, i.e., underestimation of power due to zero padding. Confidence limits are represented as well by either solid or dashed contour lines (95\% and 50\% confidence level respectively). Significance testing were performed using either background red or white noise spectra, AR(1) values of which are given in the figures for each spectrum. The method for significance testing uses peak-based critical limit significance levels. Contrary to more traditional confidence or significance level tests that

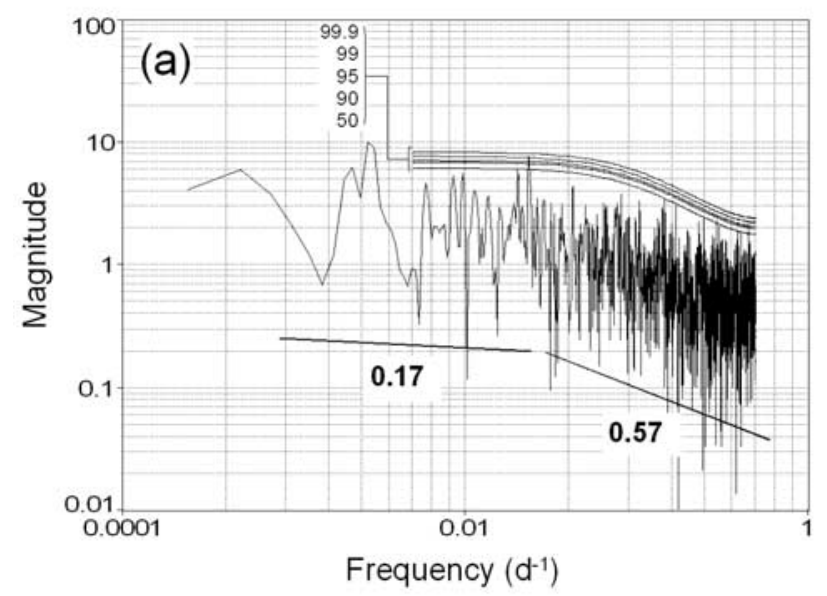

applies to a single set, this type of confidence limit is of particular merit in ascertaining the significance of the largest spectral component. In this type of test, one seeks to disprove the null hypothesis where one postulates either a white noise or a red noise background spectrum. Here, with the peak-type critical limit used, a $95 \%$ critical limit is that level where in only 1 of 20 separate random noise signals would the largest peak present achieve this height strictly by random chance, contrary to single set significance level testing, for which a standard $95 \%$ confidence limit specifies that level where $5 \%$ of the points in a single spectrum would be expected to lie above this height strictly due to random chance.

[22] The NAO local wavelet spectrum displays some very localized powerful features in the high frequencies $(\approx 1$ year and less) which could not be detected in the long-term time series as a result of the sampling frequency (Nyquist frequency of $\left.0.5 \mathrm{yr}^{-1}\right)$. Also, a significant energy band between 1.5 year and 3 years is observed, corresponding to the so-called quasi-biennal oscillation (QBO), as well as a powerful 8-year fluctuation (actually $\approx 7.8$ to 10 years),

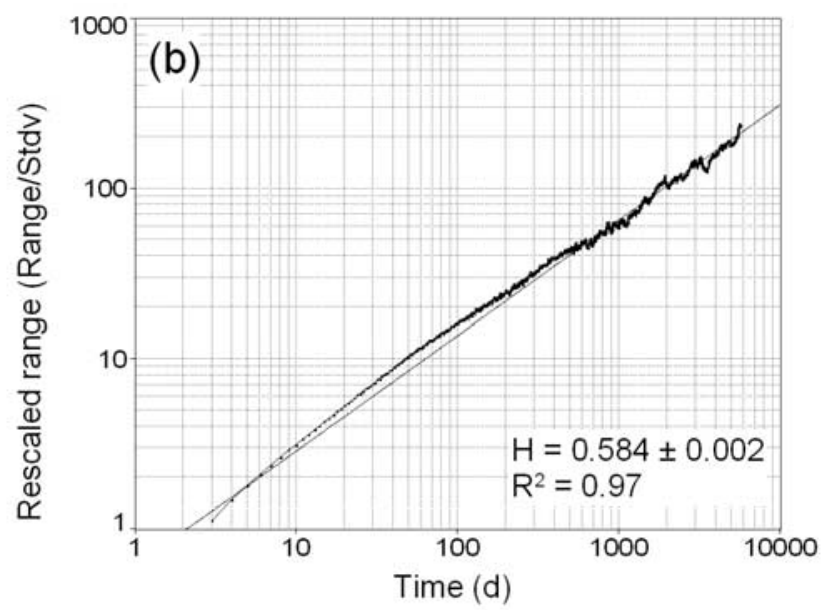

Figure 6. Rainfall Fourier spectrum and fractal dimension analysis for the mean precipitation time series. An $\operatorname{AR}(1)=0.20$ background red noise spectrum is used to define the $50 \%-99.9 \%$ confidence limits for the Fourier spectrum. 


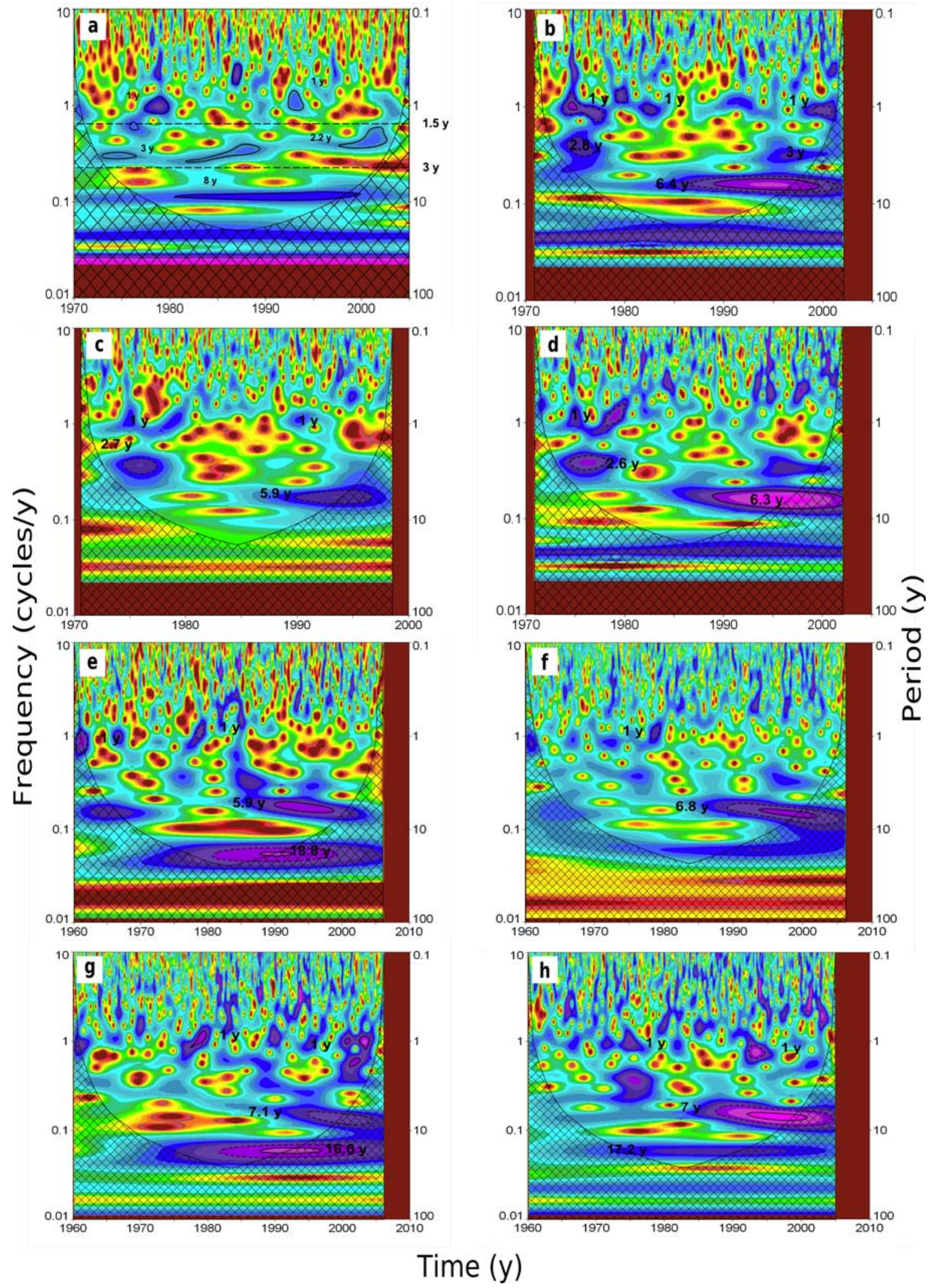

Figure 7. Local wavelet spectra of (a) daily NAO index time series and (b-h) Fatouville-Grestain, Bois-Arnault, Marcilly La-Campagne, Rennes, Chartres, Paris, and Amiens precipitation records. Solid and dashed contour lines represent the peaks with $95 \%$ and $50 \%$ confidence limit, respectively. Statistical significance was tested against red noise background spectra with $\operatorname{AR}(1)=0.62, \operatorname{AR}(1)=0.26, \operatorname{AR}(1)=$ $0.23, \operatorname{AR}(1)=0.17, \operatorname{AR}(1)=0.19, \operatorname{AR}(1)=0.16, \operatorname{AR}(1)=0.20$, and $\operatorname{AR}(1)=0.20$, respectively. 


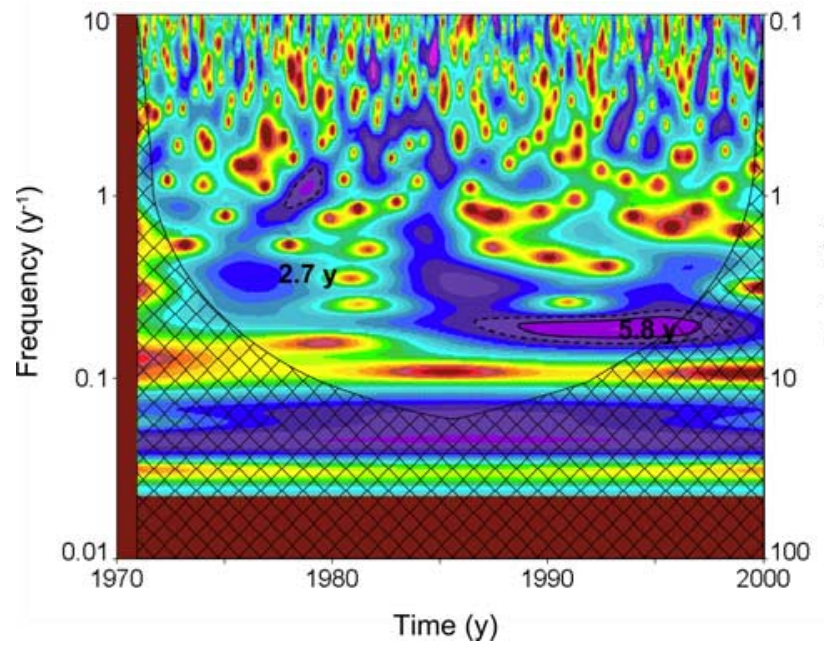

Figure 8. Local wavelet spectrum of the mean precipitation time series $\mathrm{P}_{\mathrm{m}}$ based on all seven records of northwestern France. Solid and dashed contour lines represent the peaks with $95 \%$ and $50 \%$ confidence limit, respectively $(\operatorname{AR}(1)=$ $0.20)$.

along with a deficit in power at 3- to 6-year periods. These fluctuations were already described by Hurrell et al. [2003] and Terray and Cassou [2002]. One can however notice the shift of the QBO toward slightly higher frequencies that seems to occur during the mid-80s.

[23] The continuous wavelet transforms of the several precipitation time series exhibit somewhat the same behavior, as shown in Figures $7 \mathrm{~b}-7 \mathrm{~h}$ and Figure 8. A 3.3 to 2 -year band is barely detected in precipitation series that could be related to the QBO component of NAO. This band is however only significant at the $50 \%$ confidence level, and it may be important to notice that its presence is mostly detected at the beginning of the period of study for each precipitation time series. On the other hand, a powerful band between 5 and 7.1 years, centered on a 5.8-year fluctuation for the mean precipitation time series (Figure 8) is always observed and found most of the times significant at the $95 \%$ confidence limit (sometimes 50\%), beginning in the mid-80s. This interannual fluctuation,

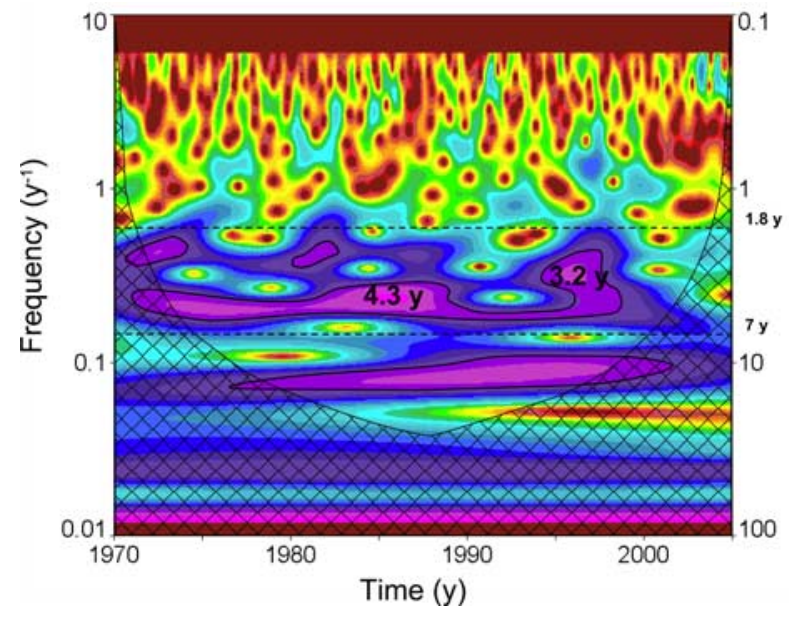

Figure 9. Local wavelet spectrum of monthly SOI for the 1970-2005 period (white noise background spectrum).

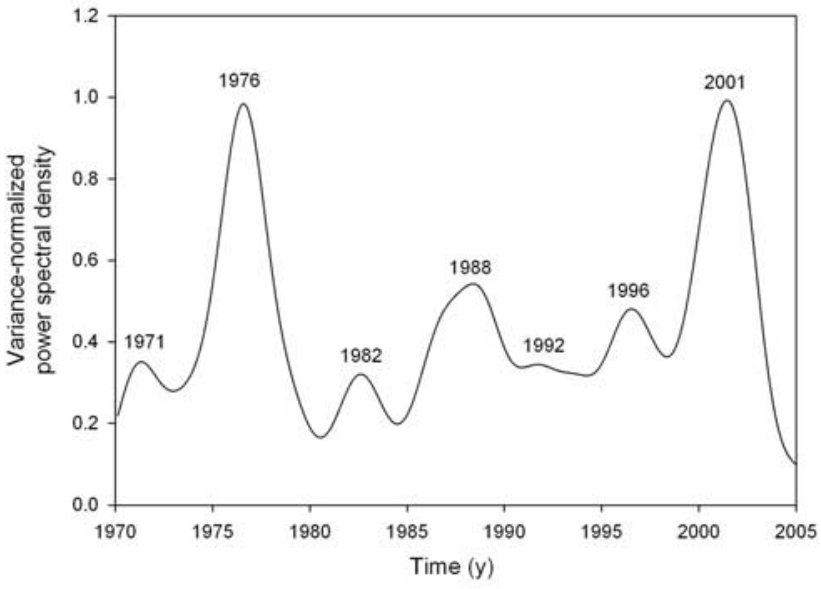

Figure 10. Scale-average power distribution of the 1.53 -year energy band of NAO. The corresponding fluctuation could be possibly modulated by a $\approx 6$-year interannual band. The scale-averaged power distribution is calculated by integrating power over monthly time intervals.

hereinafter referred to as either interannual band or 6-year interannual band, is not visible in NAO, which precisely present a deficit in power in this band.

[24] It appears difficult to associate the 8-year NAO fluctuation with the 6-year interannual band observed in precipitation. Garcia et al. [2005] having already found a 6.4-year peak in a 1866-2005 monthly time series of the SOI, it appeared rewarding to investigate the hypothesis of an SOI influence on rainfall without connection with the NAO. However, as demonstrated in Figure 9, using the same data set than that of Garcia et al. [2005], the continuous wavelet analysis of the SOI for a 1960-2005 period did not highlight any link between the SOI and rainfall series, since the 6.4-year peak could not be detected for this period. One could note that this peak was detected in the entire time series (1866 to 2005), as in the study from Garcia et al. [2005], with a Fourier analysis (Tukey filter) but was not found to be significant when tested against a background red noise $(\operatorname{AR}(1)=0.59)$.

[25] The 6-year band of precipitation cannot be associated with the interannual variability of NAO. However, the

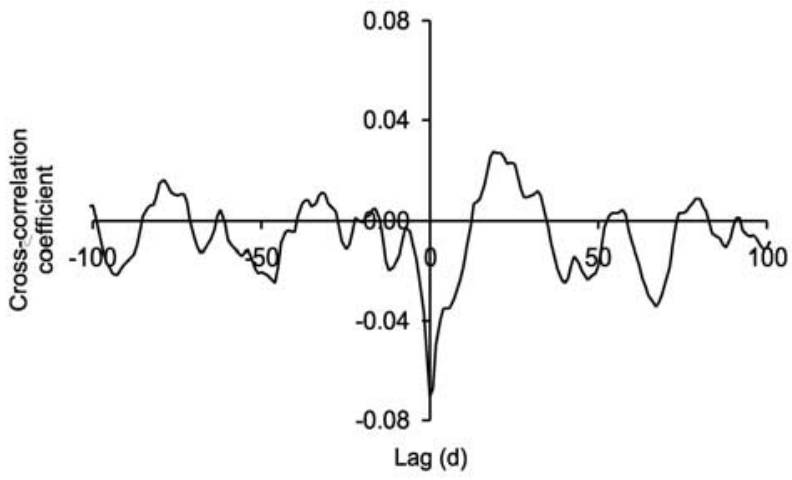

Figure 11. Cross-correlation function of the NAO and Seine river estuary precipitation time series. The two signals are uncorrelated overall. 


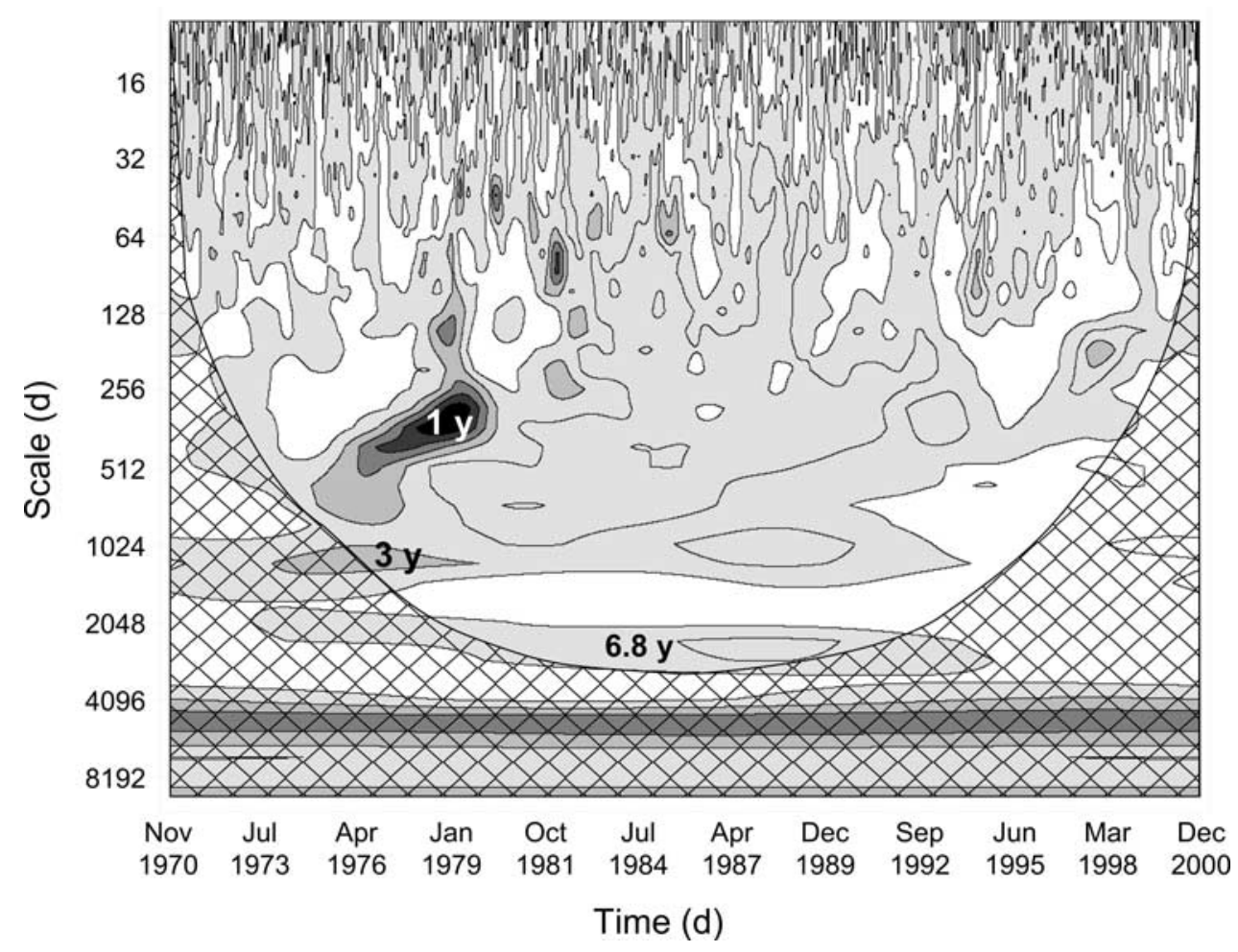

Figure 12. Cross-wavelet spectrum of daily NAO index and $\mathrm{P}_{\mathrm{m}}$ time series that evidences a progressive loss of correlation in the high-frequency band (3-year to seasonal).

occurrence in the beginning of the 90 s of the 6 -year band in precipitation seems to coincide with the shift of QBO toward slightly higher frequencies in the NAO wavelet spectrum. On the other hand, scale averaging over the 31.5-year energy band of QBO shows a possible modulation by a $\approx 6$-year interannual fluctuation (Figure 10 ). This could suggest a possible forcing of precipitation by a $\approx 6$-year climate pattern not necessarily linked to NAO, although NAO could be partly affected by this forcing as well. This point would require additional investigations.

\subsubsection{NAO/Mean Precipitation Cross Analysis}

[26] The link between NAO and rainfall over the period of study can be roughly investigated by computing the cross-correlation function between the two time series. As a matter of fact the cross-correlation function always revealed a very bad correlation (Figure 11). For instance, the crosscorrelation function between NAO and the Seine estuary precipitation record (Fatouville-Grestain) shows extremely weak cross-correlation coefficients ranging from -0.08 to 0.08 , which leads to the conclusion that NAO and precipitation are globally uncorrelated.

[27] It may possible, however, that some fluctuations in those time series could be similar: this can be checked out using cross-wavelet analysis, which provides a means for investigating the changes in correlation between two signals across time for each scale. It allows potential similar fluctuations at specific timescales to be identified.

[28] Analogously to the Fourier cross-spectral analysis, the cross-wavelet spectrum of to signals $x(t)$ and $y(t)$ is defined as

$$
W_{x y}(a, b)=W_{x}(a, b) \cdot W_{y}^{*}(a, b)
$$

where $a$ corresponds to the wavelet scale, $b$ the dimensionless time index parameter, $W_{x}(a, b)$ the $x(t)$ continuous wavelet transform and $W_{y}^{*}(a, b)$ the complex conjugate of the $y(t)$ continuous wavelet transform. Figure 12 displays the $\mathrm{NAO} / \mathrm{P}_{\mathrm{m}}$ cross-wavelet transform. A 1-year component appears very powerful on the cross-wavelet spectrum at the beginning of the period (1976-1979). One could wonder whether the presence of this peak could be due to seasonality, i.e., the signature of higher variance of the index for winter months compared to summer months. In this study, seasonality is not accounted for in the time series, in which we used daily NAO index values. However, a trade-off is offered by the method used (continuous wavelet transform) to address this issue. The signification of the 1-year peak can be easily determined thanks to the relatively good time resolution of the wavelet used here (14th-order derivative of Gaussian): this peak (more exactly, its $95 \%$ significance level for a red noise background spectrum of $\mathrm{AR}(1)=0.62$ ) spans an approximately 2-year period, ranging from August 1977 to November 1979, the peak being centered on midSeptember 1978. It would not consequently represent a contrasted variance between summer and winter months, both dry and wet seasons being merged in this same peak.

[29] A powerful QBO-like fluctuation shows off between 1973 and 1980. This fluctuation is still present between 1986 and 1991 although less powerful, and finally disappears almost totally afterward. An interannual band around 6.8 years is also detected, mainly during the middle of the overall period of study; this band disappears in the mid-90s.

[30] Comparing the results of cross-wavelet analysis to the NAO and precipitation local wavelet spectra (Figures 7 and 8), the observed loss of correlation, mainly due to the disappear- 
ance of an interannual-to-seasonal energy band $(\approx 3-0.5$-year fluctuations on the cross-wavelet spectrum), could be related to the observed shift of the QBO toward slightly higher frequencies occurring during in the beginning of the 90 s for the NAO time series, while precipitations display a $\approx 6$-year interannual band not detected in the NAO.

\section{Conclusion}

[31] Studies of rainfall variability in the context of climate change appears of primary interest. In Northern Europe, the NAO constitutes one of the major climate pattern. The NAO displays several nonstationary features that can be readily detected using continuous wavelet analyses, which are especially designed for the investigation of nonstationary signals. Within this framework, classic Fourier spectral analyses have now proven their inadequacy. According to our study, the North Atlantic Oscillation would display an increasing variability since approximately 1920 . In particular, the 8- and 44-year components show an increasing contribution to the total power of the NAO signal during the second half of the last century. On the other hand, some responses to the general issues mentioned in the introduction section can be summarized here. Our results showed that characteristic timescales can be retrieved in precipitation records, although highly nonstationary (i.e., only valid for given periods of time). Additionally, relationships between NAO and rainfall are very likely at certain timescales but may not be very obvious systematically: for instance, a 6-year band in precipitation could not be associated with the interannual variability of NAO, but its occurrence in the beginning of the $90 \mathrm{~s}$ could be related to the observed shift of the QBO toward slightly higher frequencies in the NAO time series. Finally, not only the various fluctuations are highly variable throughout a rather short time period (35 years), but also the correlation between NAO and rainfall tends to decrease during the 35-year period of study, as shown by both wavelet and cross-wavelet analyses. This trend seems particularly more marked since the $90 \mathrm{~s}$, although no direct physical link could be investigated in this study. Further investigations would be required using longer and additional time series of near-surface climate patterns. Especially, the same type of investigation of NAO temperature and precipitation relationships applied to winter periods (i.e., when those relationships are usually much stronger) would be valuable as a future research track.

[32] Acknowledgments. The authors would like to gratefully thank three anonymous reviewers for their thoughtful comments that definitely helped improving the rigor of results and interpretations throughout the entire manuscript.

\section{References}

Appenzeller, C., T. F. Stocker, and M. Anklin (1998), North Atlantic Oscillation dynamics recorded in Greenland ice cores, Science, 282 446-449.

Bojariu, R., and L. Gimeno (2003), Predictability and numerical modelling of the North Atlantic Oscillation, Earth Sci. Rev., 63(1-2), 145-168.

Bojariu, R., and G. Reverdin (2002), Large-scale variability modes of freshwater flux and precipitation over the Atlantic, Clim. Dyn., 18, 369-381.

Fernandez, I., C. N. Hernandez, and J. M. Pacheco (2003), Is the North Atlantic Oscillation just a pink noise?, Physica A, 323, 705-714.
Garcia, N. O., L. Gimeno, L. De La Torre, R. Nieto, and J. A. Anem (2005), North Atlantic Oscillation (NAO) and precipitation in Galicia (Spain), Atmosfera, 1, 25-32.

Greene, C. H., and A. J. Pershing (2000), The response of Calanus finmarchicus populations to climate variability in the northwest Atlantic: Basin-scale forcing associated with the North Atlantic Oscillation, ICES J. Mar. Sci., 57(6), 1536-1544.

Greene, C. H., A. J. Pershing, A. Conversi, B. Planque, C. Hannah, D. Sameoto, E. Head, P. C. Smith, P. C. Reid, and J. Jossi (2003), Trans-Atlantic responses of Calanus finmarchicus populations to basinscale forcing associated with the North Atlantic Oscillation, Prog. Oceanogr., 58(2-4), 301-312.

Higuchi, K., J. Huang, and A. Shabbar (1999), A wavelet characterisation of the North Atlantic Oscillation variation and its relationship to the North Atlantic sea surface temperature, Int. J. Climatol., 19, 1119-1129.

Hurrell, J. W. (1995), Decadal trends in the North Atlantic Oscillation: Regional temperatures and precipitation, Science, 269, 676-679.

Hurrell, J. W., and H. Van Loon (1997), Decadal variations in climate associated with the North Atlantic Oscillation, Clim. Change, 36, 301326.

Hurrell, J. W., Y. Kushnir, G. Ottersen, and M. Visbeck (2003), An Overview of the North Atlantic Oscillation, in The North Atlantic Oscillation: Climatic Significance and Environmental Impact, edited by J. W. Hurrell et al., Geophys. Monogr., 134, 135 pp., AGU, Washington, D. C.

Keim, B. D., R. A. Muller, and G. W. Stone (2004), Spatial and temporal variability of coastal storms in the North Atlantic Basin, Mar. Geol., $210(1-4), 7-15$

Labat, D., Y. Godderis, J. L. Probst, and J. L. Guyot (2005a), Reply to Comment of Legates et al., Adv. Water. Resour., 28, 1316-1319.

Labat, D., J. Ronchail, and J. L. Guyot (2005b), Recent advances in wavelet analyses: Part 2-Amazon, Parana, Orinoco and Congo discharges time scale variability, J. Hydrol., 314, 289-311.

Legates, D. R., H. F. Lins, and G. J. McCabe (2005), Comments on "Evidence for global runoff increase related to climate warming" by Labat et al., Adv. Water Resour., 28, 1310-1315.

Loboda, N. S., A. V. Glushkov, V. N. Khokhlov, and L. Lovett (2006), Using non-decimated wavelet decomposition to analyse time variations of North Atlantic Oscillation, eddy kinetic energy, and Ukrainian precipitation, J. Hydrol., 322, 14-24.

Lomas, M. W., and N. R. Bates (2004), Potential controls on interannual partitioning of organic carbon during the winter/spring phytoplankton bloom at the Bermuda Atlantic time-series study (BATS) site, Deep Sea Res., Part I, 51(11), 1619-1636.

Macdonald, R. W., T. Harner, and J. Fyfe (2005), Recent climate change in the Arctic and its impact on contaminant pathways and interpretation of temporal trend data, Sci. Total Environ., 342(1-3), 5-86.

Mares, I., C. Mares, and M. Mihailescu (2002), NAO impact on the summer moisture variability across Europe, Phys. Chem. Earth., 27(23-24), $1013-1017$

Parsons, L. S., and W. H. Lear (2001), Climate variability and marine ecosystem impacts: A North Atlantic perspective, Prog. Oceanogr, 49(1-4), 167-188

Pozo-Vazquez, D., M. J. Esteban-Parra, F. S. Rodrigo, and Y. Castro-Diez (2000), An analysis of the variability of the North Atlantic Oscillation in the time and the frequency domains, Int. J. Climatol., 20, 1675-1692.

Rogers, J. C. (1997), North Atlantic storm track variability and its association to the North Atlantic Oscillation and climate variability of northern Europe, J. Clim., 10, 1635-1647.

Tank, A. M. G., et al. (2002), Daily dataset of 20th-century surface air temperature and precipitation series for the European climate assessment, Int. J. Climatol., 22(12), 1441-1453.

Terray, L., and C. Cassou (2002), Tropical Atlantic sea surface temperature forcing of quasi-decadal climate variability over the North AtlanticEuropean region, J. Clim., 15, 3170-3187.

Torrence, C., and G. P. Compo (1998), A practical guide to wavelet analysis, Bull. Am. Meteorol. Soc., 79, 61-78.

Ulbrich, U., and M. Christoph (1999), A shift of the NAO and increasing storm track activity over Europe due to anthropogenic greenhouse gas forcing, Clim. Dyn., 15, 551-559.

Ulbrich, U., M. Christoph, J. G. Pinto, and J. Corte-Real (1999), Dependence of winter precipitation over Portugal on NAO and baroclinic wave activity, Int. J. Climatol., 19, 379-390.

J. Deloffre, J. P. Dupont, A. Durand, B. Laignel, N. Massei, and D. Valdes, UMR 6143, Continental and Coastal Morphodynamics, Department of Geology, CNRS, University of Rouen, F-76821 Mont-Saint-Aignan Cedex, France. (nicolas.massei@univ-rouen.fr) 